\title{
Accreditation is not a One-time Process: Quality Assessment of Intensive Care Unit during Post-NABH Accreditation Period in a Tertiary Care Hospital
}

\author{
${ }^{1}$ VK Tadia, ${ }^{2}$ Monalisa, ${ }^{3}$ Suneeta Dubey
}

\begin{abstract}
Accreditation is an integral part of quality and it is not a onetime process. This study was done to know the extent to which hospitals maintain the standards after obtaining accreditation. This study tries to find out the gaps in standards during the postaccreditation period. The objective of the study was to assess the policies of the intensive care unit (ICU) with reference to standard protocols of the National Accreditation Board for Hospital and Health Care Providers (NABH) and measures taken by the management to maintain the standards. Data was collected from a 285-bedded $\mathrm{NABH}$-accredited hospital that had five ICUs and four recovery rooms by means of nonparticipant observation, semistructured interviews. Data on indicators was collected by using the hospital management information system; the questionnaire on satisfaction was filled by 30 patients/relatives who were admitted in the ICU for more than a week. Quality team was interviewed to know the perception of the management toward quality and accreditation. To know the compliance of the staff to the NABH standards, a surprise check was done in three ICUs of the hospital.

Data analysis showed that the organization was not able to maintain the standards, as it had done at the time of accreditation. The quality team strongly accepted that accreditation helps in maintaining and improving quality, whereas the data from ICUs showed a wide variation in compliance. Three ICUs from the same hospital were having different compliance rates for standards, which shows that staff was not aware about the standard protocol to be followed. The patient-satisfaction questionnaire also showed that the patients were not satisfied with the services given.
\end{abstract}

Keywords: Accreditation, Continuous quality improvement, Postaccreditation, Quality.

How to cite this article: Tadia VK, Monalisa, Dubey S. Accreditation is not a One-time Process: Quality Assessment of Intensive Care Unit during Post-NABH Accreditation Period in a Tertiary Care Hospital. Int J Res Foundation Hosp Healthc Adm 2017;5(1):29-41.

Source of support: Nil

Conflict of interest: None

\footnotetext{
${ }^{1}$ Senior Resident Administrator, ${ }^{2}$ Quality Manager, ${ }^{3}$ Associate Medical Director

${ }^{1}$ Department of Hospital Administration, All India Institute of Medical Sciences, New Delhi, India

${ }^{2,3}$ Dr. Shroff's Charity Eye Hospital, New Delhi, India

Corresponding Author: VK Tadia, Senior Resident Administrator, Department of Hospital Administration, All India Institute of Medical Sciences, New Delhi, India, e-mail: vijay@ vijaytadia.org
}

\section{INTRODUCTION}

The concept of accreditation first came into vogue in the USA in 1910 to determine the effectiveness of treatment provided to patients. In 1919, the hospital standardization program came into existence, which was set up by the American College of Surgeons. In 1953, the Joint Commission on Accreditation of Health Care Organization (JCAHO) was founded, which later became the Joint Commission International (JCI) in $2007^{1}$ In India, the premier accreditation body is the NABH, which constitutes the board of the quality council of India. The aim behind the setting up of the NABH was to enhance the health care system and promote continuous quality improvement and safety for the patients. According to the NABH website, 197 hospitals in India were accredited and 600 hospitals had applied for accreditation. ${ }^{2}$ These figures show the important role played by accreditation in the health-care industry. The accreditation process gives an opportunity to assess the existing setup, processes, and activities to turn them around as process maps, standard operating procedures (SOPs), standards, and norms as defined by different accreditation agencies.

Accreditation works as a framework for the quality of care given in a hospital. Accreditation sets a standard for the organization to follow. Performance below that standard is not accepted by the accreditation board. It gives a set of objectives and goals, which help the organization to achieve quality of care, which if not adhered to can lead to the cancellation of accreditation.

\section{Necessity of maintaining Quality after Accreditation}

The postaccreditation period is very crucial, as whatever the organization has strived to attain during the process of getting accreditation should not go in vain. Once the basic structure has been formulated and function and activities finalized and optimized, the continuous quality improvement should become the culture of the organization. If the standards are not maintained as they were at the time of accreditation the quality of care will suffer and the license may be cancelled by the accreditation agency. Getting accreditation is not enough; one has to 
go beyond that to maintain the standards at all times post accreditation.

\section{Rationale of the Study}

To help improve the quality of care provided, various accreditation agencies were established worldwide. A set of standards were given by these accreditation agencies, which not only helps one to know where an organization stands in term of quality, but also helps to maintain and continuously improve the standards.

In various hospitals the quality indicators are not monitored once accreditation is achieved; therefore, the graph for quality of care declines which impacts the image of the hospital and in this competitive scenario, no organization can afford this.

Today in India, various accreditation agencies are active which are nongovernmental, nonprofit organizations. Among them, the $\mathrm{NABH}$ is one of the important organizations. It has given accreditation to more than 200 hospitals and more than 600 hospitals have applied for it. Accreditation is an important part of maintaining and improving quality. Just getting done the accreditation is not enough; quality has to be maintained and continuous improvement is necessary.

This study was done to check whether an organization was able to maintain the standards and benchmarks set at the time of getting accreditation or was it only a one-time process.

\section{Reason for selecting the ICU}

The ICU was chosen to study quality indicators because:

- It is the area where one needs to be very careful as patients are in a critical condition and staff-patient ratio is sometimes inadequate \& standards of care set up by the hospital are not achieved.

- It is very important to follow the standard policies and procedures in every part of the hospital, but it becomes more important in the ICU because the patient care in the ICU is directly related to patient satisfaction and the image of the hospital.

- It helps in generating a major portion of revenue for the hospital.

- It accounts for the major portion of expenses too.

\section{Scope of the Study}

The study was conducted in an NABH-accredited corporate hospital in New Delhi. Data was especially collected for the ICUs. The perception of the hospital staff on accreditation and need of maintaining quality was obtained through a semistructured interview. Quality indicators were collected from the Hospital Information
Management System which were then compared with benchmarks. Questionnaires were used to rate the satisfaction level of the patients who were admitted in the ICU.

\section{Objective of the Study}

- To assess the hospital policies with standard protocols of the NABH in the ICU.

- To assess:

- Perception of staff toward quality improvement in post accreditation period.

- The measures taken by the health care organization to maintain quality.

- To assess the satisfaction level of patients and their relatives in the ICU of the NABH-accredited hospital with regard to the quality of care given.

\section{Review of Literature}

Accreditation is an external assessment of any organization's performance against a predetermined set of standards which are measurable to an extent possible.

A study done by the World Health Organization $(\mathrm{WHO})^{3}$ describes the structure and activities at the national and international level to promote quality in health care, quality tools used in various countries, and initiatives in health services' accreditation. The summaries stated the status of accreditation in various countries at present. The data helped in knowing the natural history of accreditation in various countries. The survey was done in 47 countries. This worldwide study undertaken by the WHO showed the need and importance of the accreditation in today's scenario and the need of the traditional accreditation agency to adapt to the changing demands and needs in order to survive. ${ }^{3}$

Tabrizi et $\mathrm{al}^{4}$ did a systemic review of Medline and PubMed using keywords "accreditation model" and "hospital." The articles were searched from January 1985 to December 2010 which resulted in 2,369 articles. The result of the study showed that most cited program is the US-based JCAHO/JCI, which was referred in 91\% of articles reviewed in the study. The JCAHO meets all the attributes at the highest level with main focus on quality and emphasis on best practice. The reviewed articles showed the list of attributes that can assist in choosing an accreditation model. According to the study results, the JCAHO is the most comprehensive for reference purposes. 4

The above two case studies showed the need of accreditation worldwide and its importance. The study done by the WHO revealed the different country's accreditation systems and the structure and improvements necessary in an accreditation program. The second study shows the 
advantages and disadvantages of various accreditation models and a reference for the accreditation model.

Gopinathan ${ }^{5}$ conducted a study over the period of a month in 2010. The result showed that hospitals only satisfy three standards - access, assessment, and continuity of care (AAC) - and two standards of care of patients. This study documented the gap between actual standards of the NABH and the existing standards in the hospital. ${ }^{5}$

Salmon et $\mathrm{al}^{6}$ conducted a study in South Africa in October 2003 to know the impact of accreditation on the quality of hospital care. The main question addressed by this study was whether there is any improvement in quality after a hospital goes through accreditation. After 2 years, the hospital's performance that was intervened increased from 38 to $76 \%$, whereas the control hospital did not show any remarkable progress (37-38\%). This was the first study done to assess the impact of hospital accreditation. ${ }^{6}$

A similar study was conducted in Lebanon to know the impact of accreditation on quality of care. ${ }^{7}$ The objective of the study was to know the views of health care professionals, especially nurses, on quality and accreditation. All the hospitals that passed the national accreditation survey were included. Totally, 1,048 registered nurses from 59 hospitals were selected. The results showed that improvement in quality had been noted by nurses after accreditation, and they felt that accreditation is a good tool for improving quality of care. ${ }^{7}$

\section{MATERIALS AND METHODS}

\section{Research Design}

\section{Type of the Study}

A mixed-method study (quantitative and qualitative) was undertaken. Emphasis was given on current practices followed by hospital, management views on quality, patient satisfaction, and quality indicators maintained by the hospital. Nine quality indicators and the NABH checklist were used. In this study, the quality team staff were interviewed with the help of semistructured interviews to know their views on quality and accreditation. Patient satisfaction data was collected through questionnaires.

\section{Area of Study}

Delhi is the capital of India with a population of 22 million in 2011 - the world's second most populated and India's largest city in terms of area. The total number of hospitals in Delhi was 94, among which 38 were accredited. ${ }^{4}$

\section{Frame of the Study}

A corporate NABH-accredited hospital, which had the maximum number of ICU beds out of the sample selected was considered for this study. The ICU was assessed for quality indicators and procedures and policies followed over a period of time. Data was collected from three ICUs of the hospital. Each ICU was 15 bedded, and data was collected in three phases. In the first phase, the quality team was interviewed; in the second phase, a surprise check was done on staff of the ICU with the help of checklist, which included NABH standards; and in the third phase, the data related to quality indicators was collected for 1 year (Jan 2012-Dec 2012).

\section{Sampling Design}

\section{Sample Selection}

Delhi had 38 accredited hospitals at that time. A list of all these hospitals was prepared, and all the corporate hospitals that were NABH accredited were selected. Further, these hospitals were shortlisted based on the availability of ICUs and number of ICU beds. The hospitals with a minimum of 3 ICUs and 10 beds in each ICU were selected for better results from the study. As quality-related data is highly confidential, the study was started after obtaining permission from one of these hospitals.

\section{Setting for the Study}

The hospital was a corporate hospital established in 1988. It had a strength of 285 beds, among which there were five ICUs and four recovery rooms other than wards. The hospital got NABH accreditation in 2008, and after that continuous renewal was done. The recent renewal was done in 2011, where it successfully met all the criteria. In 2010, the hospital also got the JCI accreditation. The hospital serves not only the population of Delhi and National Capital Region, but also that from around the country and foreign patients.

\section{Data Collection Method}

Data was collected over a period of a month (April-May 2013), which included primary as well as secondary data. Primary data was collected by means of direct nonparticipant observation. Interviews were conducted with six quality control officers, who were directly or indirectly responsible to maintain the quality in the ICU. The nine indicators were collected from hospital management information system (HMIS) for 1 year. To know the patient satisfaction, a close-ended questionnaire was used, which was filled by 30 respondents.

\section{Quantitative Data}

The quantitative data was collected as follows. 


\section{Quality Indicators in ICU}

There were 35 quality indicators pertaining to the $\mathrm{NABH}$; out of them, 11 were mandatory for the NABH and the Quality Council of India for reporting purposes. The purpose of selecting the indicators was to collect the data for a year and compare those data at the time of accreditation.

Nine indicators, applicable to the ICU were

1. Needle stick injury (NSI);

2. Central line-associated blood stream infection;

3. Incidence of pressure sores;

4. Catheter-associated urinary tract infection (CAUTI);

5. Ventilator-associated pneumonia (VAP);

6. Surgical site infection (SSI);

7. Fall rate;

8. Reintubation rate within 48 hours of extubation; and

9. Return to ICU within 24 hours of discharge.

Questionnaire was filled on patient satisfaction by 30 respondents.

Inclusion criteria: Questionnaire was given to only patients/relatives who were admitted in the ICU for more than three weeks. Data was collected for a period of 1 month.

A checklist was prepared for a surprise check of the ICU to check whether staff were following the criteria or not. The checklist was based on the NABH standards, which are related to the ICU. The criteria applicable to the ICU were selected.

The standards on which the checklist was made are as follows:

- Care of patient (COP) 4: Documented policies and procedures guide the care of patients requiring cardiopulmonary resuscitation.

- COP 6: Documented procedure guides the performance of various procedures.

- COP 8: Documented policies and procedures guide the COP in the intensive care and high-dependency units.

- COP 16: Documented policies and procedures guide appropriate pain management.

- COP 20: Documented policies and procedures guide the end-of-life care.

- Hospital Infection Control 9: The infection control program is supported by the management and includes training of staff.

\section{Qualitative Data}

Primary data was collected in the form of face-to-face interviews. Semistructured interviews were conducted based on the availability of members of the quality team. Before taking the interview, verbal and written consent was taken from the respondents.
Table 1: Objective and methodology used for data collection

\begin{tabular}{|c|c|}
\hline Objectives & Methodology \\
\hline $\begin{array}{l}\text { To assess the policies with standards of } \\
\text { the NABH in the ICU }\end{array}$ & $\begin{array}{l}\text { Indicator checklist } \\
\text { and policy of the ICU }\end{array}$ \\
\hline $\begin{array}{l}\text { To assess management perception } \\
\text { toward quality management in post- } \\
\text { NABH accreditation period }\end{array}$ & $\begin{array}{l}\text { Semistructured } \\
\text { interview }\end{array}$ \\
\hline $\begin{array}{l}\text { To assess the measures taken by the } \\
\text { hospital to maintain the quality }\end{array}$ & $\begin{array}{l}\text { Semistructured } \\
\text { interview }\end{array}$ \\
\hline $\begin{array}{l}\text { To assess patients'/relatives' satisfaction } \\
\text { level }\end{array}$ & $\begin{array}{l}\text { Patient satisfaction } \\
\text { questionnaire }\end{array}$ \\
\hline
\end{tabular}

- Quality team members - The staff, who were part of the quality team and responsible for maintaining quality and accreditation standard in the ICU, were interviewed.

- Patients/relatives - 30 patients/relatives who were admitted in the ICU for more than 3 weeks were asked to fill the questionnaire to know the satisfaction level.

\section{Objectives and Methodology used}

The objectives and the methodology used for data collection is given in Table 1

\section{RESULTS AND FINDINGS}

\section{Quantitative Methods}

\section{Patient Satisfaction Questionnaire Analysis}

The questionnaire contained 19 questions related to satisfaction of services. Questionnaires were filled by the 30 patients/relatives, who are admitted in the ICU for more than 3 weeks. The questions were further classified for the ease of analysis into three categories (Table 2).

Satisfaction related to

- Services

- Hygiene

- Information

Services include care provided by staff, nursing care, attitude of staff toward patients, and charges of services provided. In the hygiene category, questions that were asked related to sanitation facilities in the hospital. Information included whether patients were given all the necessary information regarding procedure, charges, and duration of treatment. The patient satisfaction questionnaire is given in Table 3.

The questions in various categories were as follows.

Table 2: Categorical analysis of patient satisfaction questionnaire

\begin{tabular}{llll}
\hline Categories & Yes & No & Sometimes \\
\hline Services & $172(63.70 \%)$ & $55(20.37 \%)$ & $33(12.22 \%)$ \\
Hygiene & $90(100 \%)$ & 0 & 0 \\
Information & $113(53.80 \%)$ & $77(36.66 \%)$ & $20(9.52 \%)$ \\
\hline
\end{tabular}


Table 3: Patient satisfaction questionnaire analysis

\begin{tabular}{|c|c|c|c|c|}
\hline Categories & Questions & Yes & No & Sometimes \\
\hline \multirow[t]{3}{*}{ Hygiene } & Staff are professional and neat in appearance & 30 & 0 & 0 \\
\hline & Clean and comfortable environment in hospital & 30 & 0 & 0 \\
\hline & Are you satisfied with the cleanliness of the hospital? & 30 & 0 & 0 \\
\hline \multirow[t]{9}{*}{ Service } & Up-to-date and well-maintained medical facilities and equipment & 25 & 5 & 0 \\
\hline & Service provided, whenever needed & 18 & 3 & 9 \\
\hline & Consistency of charges in services provided & 23 & 5 & 2 \\
\hline & Responsiveness is displayed by staff & 22 & 6 & 2 \\
\hline & Patient is treated with dignity and respect & 24 & 5 & 1 \\
\hline & Privacy is provided during treatment & 23 & 6 & 1 \\
\hline & Affordable charges payable for services rendered & 17 & 6 & 7 \\
\hline & Are you satisfied with services provided? & 3 & 13 & 4 \\
\hline & Are you satisfied with continuity of care (follow-up) provided by organization? & 17 & 6 & 7 \\
\hline \multirow[t]{7}{*}{ Information } & Consent form is filled and explained before any procedure done & 20 & 6 & 4 \\
\hline & Information is provided regarding services available & 21 & 7 & 2 \\
\hline & Thoroughness of explanation of medical condition of the patient & 8 & 20 & 2 \\
\hline & Every procedure done is explained well & 14 & 14 & 2 \\
\hline & You were given a chance to ask questions and make choice of treatment & 9 & 17 & 4 \\
\hline & Last decision of treatments depends on you & 20 & 7 & 3 \\
\hline & Obtain feedback and patient kept informed & 21 & 6 & 3 \\
\hline
\end{tabular}

\section{Services}

- Up-to-date and well-maintained medical facilities and equipment.

- Services provided, whenever needed.

- Consistency of charges in services provided.

- Responsiveness displayed by staff.

- Patient treated with dignity and respect.

- Privacy was maintained during treatment.

- Affordable charges payable for services rendered.

- Satisfaction with the services provided.

- Satisfaction with the continuity of care (follow-up) provided by the organization.

\section{Hygiene}

- Clean and comfortable environment in hospital.

- Staff were professional and neat in appearance.

- Satisfaction with cleanliness of the hospital.

\section{Information}

- Consent form was filled and explained before any procedure done.

- Information was provided regarding services available.

- Thoroughness of explanation of medical condition of patient.

- Every procedure done was explained well.

- Chance was given to ask questions and make choice of treatment.

- Last decision of treatment depends on patient.

- Feedback was obtained and patient kept informed.

\section{Analysis of Questionnaire}

The categorical analysis of the patient questionnaires (Table 2) showed the patient satisfaction level in different categories. Patients were highly satisfied with hygiene and cleanliness, whereas satisfaction level was very low for services $(63.70 \%)$ and information $(53.80 \%)$ provided to patients.

Percentage of respondents satisfied with services provided in the hospital was $63.70 \%$, whereas $20.37 \%$ patients were not satisfied with the services provided in the hospital and $12.22 \%$ people were sometimes satisfied. Respondents were highly dissatisfied with information provided to them regarding services available to them, such as treatment available and information regarding best treatment available. Only $53.80 \%$ respondents said that they were given proper information regarding treatment available, patient's condition, and best possible treatment for patient.

The analysis of the patient satisfaction questionnaire (Table 3) revealed that the area for dissatisfaction was different for every patient/relative(s). For instance, 9 out of 30 patient/relatives said they were not/sometimes given information regarding services available in the hospital and the last choice of treatment was decided by the doctors. Information regarding procedure performed was given to 14 patients, whereas 14 patients said it was not explained. In case of explaining the patient's medical condition, only 8 relatives said it was explained well; 20 relatives were not informed about patient's condition. 
The major area where patients were not satisfied with services was follow-up care. Among 30 respondents, 6 said they were not given proper care while doing follow-up. Only 17 patient/relatives said they were given full attention at the time of follow-up. Out of 30 patients, only 3 patients said they were satisfied with services provided to them.

On the contrary, 25 patients/relatives said that they were satisfied with technology available in the hospital. Most of the patients/relatives accepted that they were given a chance to ask questions regarding treatment.

Analysis of checklist: The checklist that was made on the NABH standards was further categorized into three:

- Patient care-centered standards

- Continuous quality improvement standards

- Hospital infection control standards.

The checklist was analyzed based on of responses recorded by nonparticipatory observations. The data was collected in three different ICUs of the same hospital and compared. The checklist is given in Table 4 .
The surprise check was done in three ICUs of the hospital based on the checklist; the results are shown in Table 5 .

The checklist, which was used for surprise check in the ICUs, was based on the NABH standards, which were divided into three categories based on objectives illustrated by the NABH. The three ICUs, where surprise checks were done, showed variations in similar objectives and standards. The ICU A and B followed $60 \%$ patientcentered care, whereas in ICU C, it was followed only by $35 \%$. There was wide variation in the same organization in following the procedures and policies. Similarly, for hospital infection control, it was different for all the three ICUs. The continuous quality improvement (CQI) standards were followed similarly in all the three ICUs. No ICU followed any standard by $100 \%$. The compliance was very less and different in all the three ICUs.

Analysis showed $60 \%$ patient care standards were followed in ICU A and ICU B, whereas ICU C followed only $35 \%$. In case of continuous quality improvement standards, the standards were followed by $42.85 \%$, which

Table 4: Checklist

\begin{tabular}{|c|c|c|c|}
\hline Standards & & Yes & No \\
\hline \multirow[t]{19}{*}{ Patient Care Standards } & Standard operating procedure is available in the ICU & & \\
\hline & Documented procedure to guide the patient care & & \\
\hline & Standard operating procedure includes how the care is organized & & \\
\hline & $\begin{array}{l}\text { Standard operating procedure includes what is to be monitored in a patient with reference } \\
\text { to specific situation }\end{array}$ & & \\
\hline & The hospital has criteria for admission in the ICU & & \\
\hline & The staff are aware about the criteria for admission of the patient in the ICU & & \\
\hline & Organization has criteria for transferring the patient to the other hospital from ICU & & \\
\hline & Staff working in the ICU are aware of criteria about shifting the patient to other hospital & & \\
\hline & Number of equipment available in the ICU is adequate in comparison to service provided & & \\
\hline & There is defined procedure followed in case of bed shortage in the ICU & & \\
\hline & Staff are aware of what needs to be done in case of shortage of bed in the ICU & & \\
\hline & Patients are screened for pain & & \\
\hline & Detailed and periodic assessment is done of patients suffering from pain & & \\
\hline & Intensive care unit has documented policies and procedure to guide the end-of-life care & & \\
\hline & $\begin{array}{l}\text { The department also addresses the identification of the unique needs of such patients and } \\
\text { family }\end{array}$ & & \\
\hline & Staff are educated and trained in end-of-life care & & \\
\hline & $\begin{array}{l}\text { Documented policies and procedures to guide the monitoring of the patients after } \\
\text { medication administration }\end{array}$ & & \\
\hline & Close monitoring situations are defined by organization & & \\
\hline & Monitoring of the patient after medication is done in a collaborative manner & & \\
\hline
\end{tabular}

Table 5: Categorical analysis of checklist

\begin{tabular}{|c|c|c|c|c|c|c|}
\hline \multirow[b]{2}{*}{ Categories } & \multicolumn{2}{|c|}{$I C \cup A$} & \multicolumn{2}{|c|}{$I C U B$} & \multicolumn{2}{|c|}{ ICU C } \\
\hline & Following & Not following & Following & Not following & Following & Not following \\
\hline Patient care-centered standards & $12(60 \%)$ & $8(40 \%)$ & $12(60 \%)$ & $8(40 \%)$ & $7(35 \%)$ & $13(65 \%)$ \\
\hline $\begin{array}{l}\text { Continuous quality improvement } \\
\text { standards }\end{array}$ & $3(42.85 \%)$ & $4(57.14 \%)$ & $3(42.85 \%)$ & $4(57.14 \%)$ & $3(42.85 \%)$ & $4(57.14 \%)$ \\
\hline Hospital infection control standards & $8(80 \%)$ & $2(20 \%)$ & $5(50 \%)$ & $5(50 \%)$ & $6(60 \%)$ & $4(40 \%)$ \\
\hline
\end{tabular}


was same for all three ICUs. Hospital infection control standards showed wide variations in the three ICUs. ICU A showed $80 \%$ compliance, whereas ICU B and ICU C showed compliance respectively, by 50 and $60 \%$.

The possible reason for this wide variation was lack of knowledge of staff about SOPs and lack of motivation for following the standard procedures.

\section{Analysis of NABH Indicators}

The nine indicators were selected specifically for the ICU. The data was collected on these nine indicators for the year 2012 (Jan-Dec) and compared with the benchmark set by the hospital itself, at the time of the first accreditation in 2008.

\section{Needle Stick Injury}

The NSI data was collected and calculated in the hospital by the below formula:

\section{Number of NSIs reported in a month Total number of inpatient days in a month}

The chart and table (Graph 1) clearly show that the incidence of NSI was very high from the benchmark set for the hospital. Only in the month of October, the rate was below the standard. The possible reason illustrated by the quality team officer was ignorance by health care workers in handling sharps.

\section{Central Line-associated Blood Stream Infection}

According to the hospital's policy, Central Line Associated Bloodstream Infection (CLABSI) is "A laboratory confirmed bloodstream infection where central line or umbilical catheter was in place for $>2$ calendar days when all elements of the Laboratory-confirmed Blood Stream Infection (LCBI) infection criteria were first present together, with day of device placement being day 1."

The CLABSI cases in ICU were recorded through HMIS and calculated by below formula:

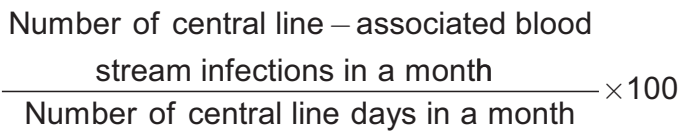

The CLABSI rates were highest in May and June (Graph 2). Possible reason illustrated was not maintaining the aseptic conditions while doing the procedure. One more reason noted was lack of central line/intravenous line care by doctors and nurses. After noticing the wide variation, measures were taken to reduce it. The measures were effective, which can be seen by the trend; there was decrease in the CLABSI rate. Overall, the organization needed to control the rates as over a period of time rates were high. This clearly showed that organization was not able to maintain the standards set by it.

\section{Incidence of Pressure Sores}

Incidence of pressure sores was calculated in the ICU and compared with the benchmark. The formula that was used is given below:

\section{Number of incidence of pressure scores developed after admission to the hospital Patient days $\times 100$}

Hospital was able to maintain the trend for a period of time (Graph 3). Only in the month of October, there was slight deviation from standard. The possible reason stated was lack of proper nursing care in the ICU as illustrated by management.

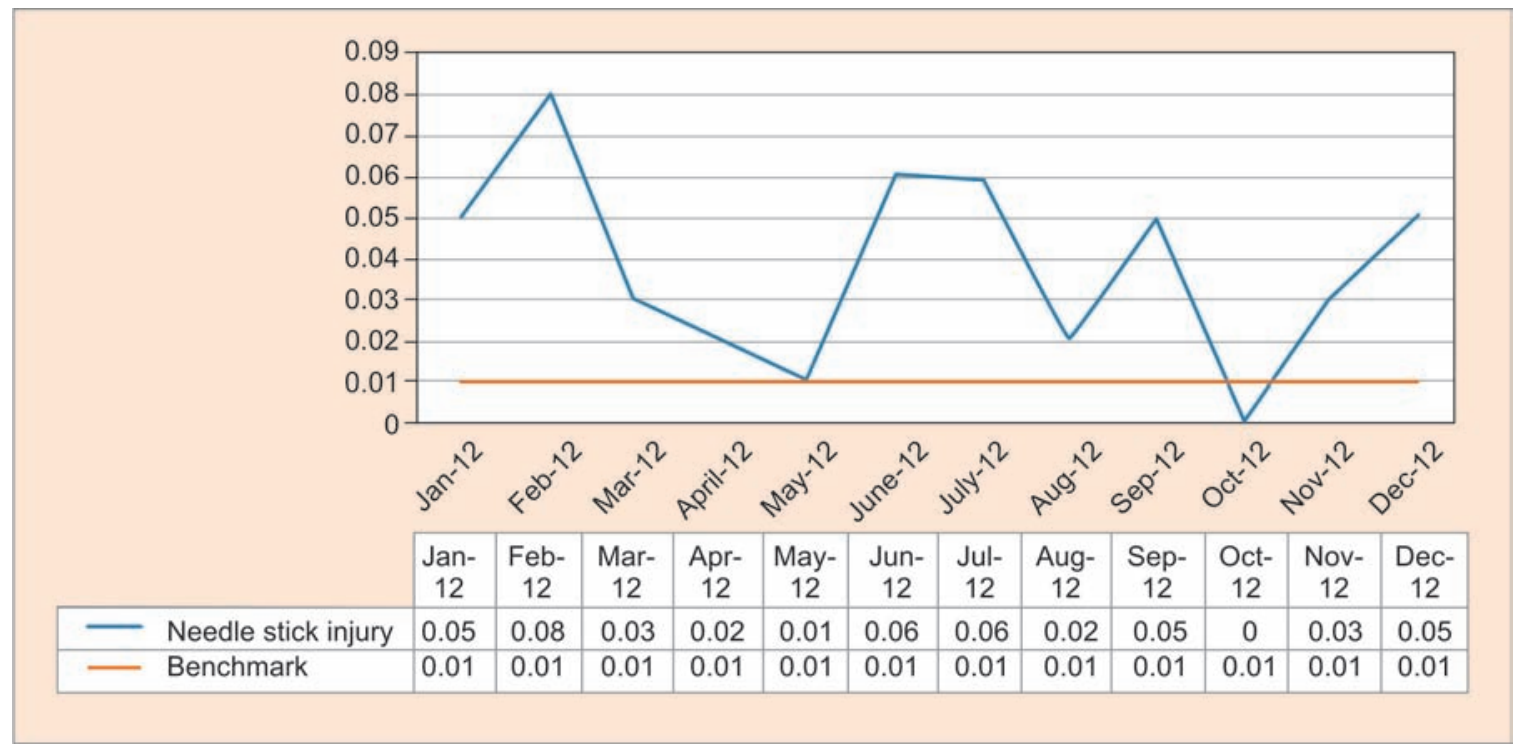

Graph 1: Comparison of annual NSI data with benchmark 


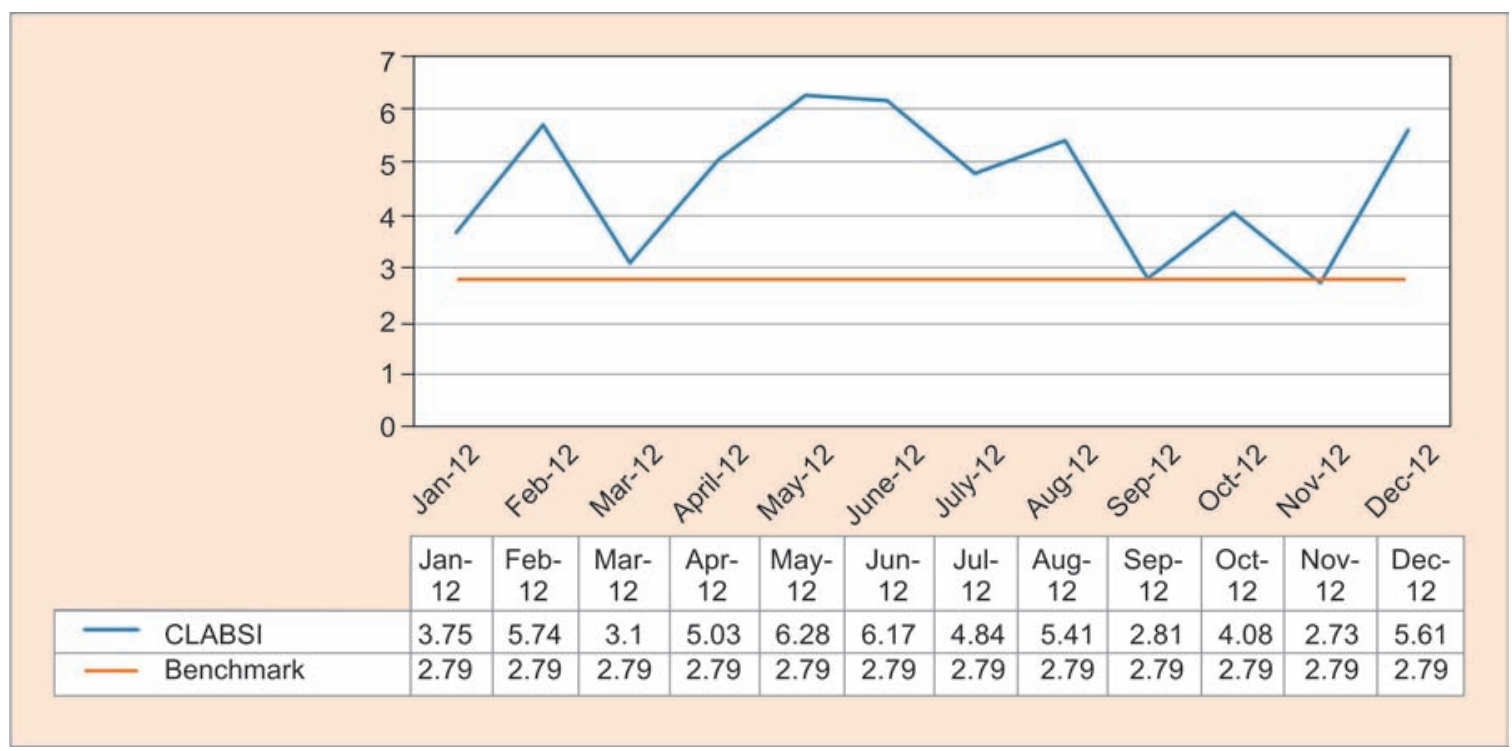

Graph 2: Comparison of annual CLABSI data with benchmark

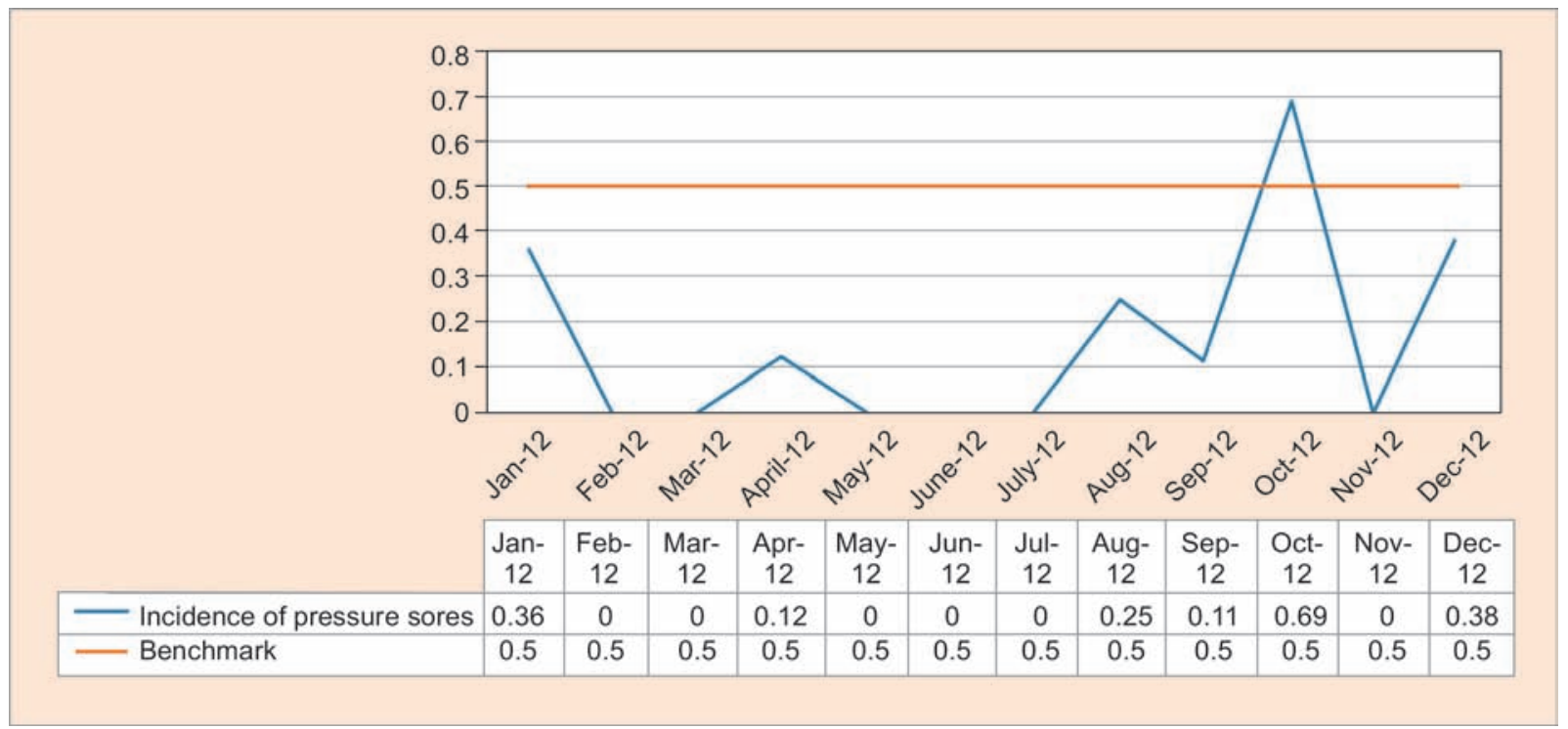

Graph 3: Comparison of annual incidence of pressure sores data with benchmark

\section{Catheter-associated Urinary Tract Infection}

Catheter-associated urinary tract infection was another indicator that was very important to monitor in patients admitted to the ICU for more than a week, and if it is not taken care of this results not only in increase of the length of stay but also decrease in the revenue of the hospital. The CAUTI in the department was calculated based on the formula given below:

$$
\frac{\text { Number of CAUTI }}{\text { Number of catheter days }}
$$

Though the benchmark kept was 4.02, any value from 0 to 4.82 was considered good (Graph 4 ). The values were less than 4.02, which is already a high benchmark given by the national health care safety, and the organization was able to maintain it.

\section{Ventilator-associated Pneumonia}

In a mechanically ventilated patient, pneumonia is identified by using a combination of radiologic, clinical, and laboratory criteria.

$$
\frac{\text { Number of VAP }}{\text { Number of ventilator days }} \times 100
$$

The highest deviation was observed in April, May, July, and August (Graph 5), where the rates were double from the standard set by the organization, which was due to lack of ventilator maintenance after patient was discharged and in some cases it was long device days. It was noticed by the infection control committee and measures were taken to reduce it; the trend shows that measures were effective too. 


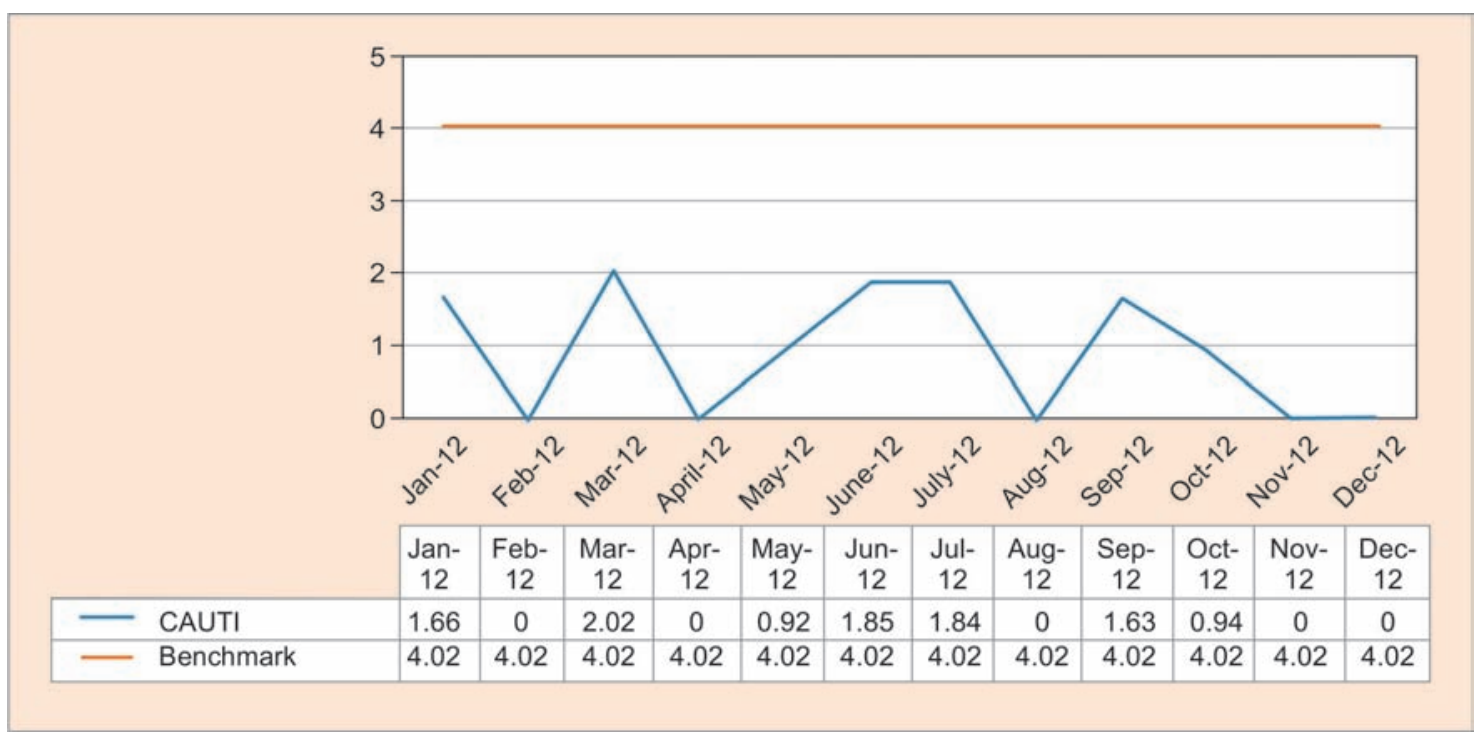

Graph 4: Comparison of annual CAUTI data with benchmark

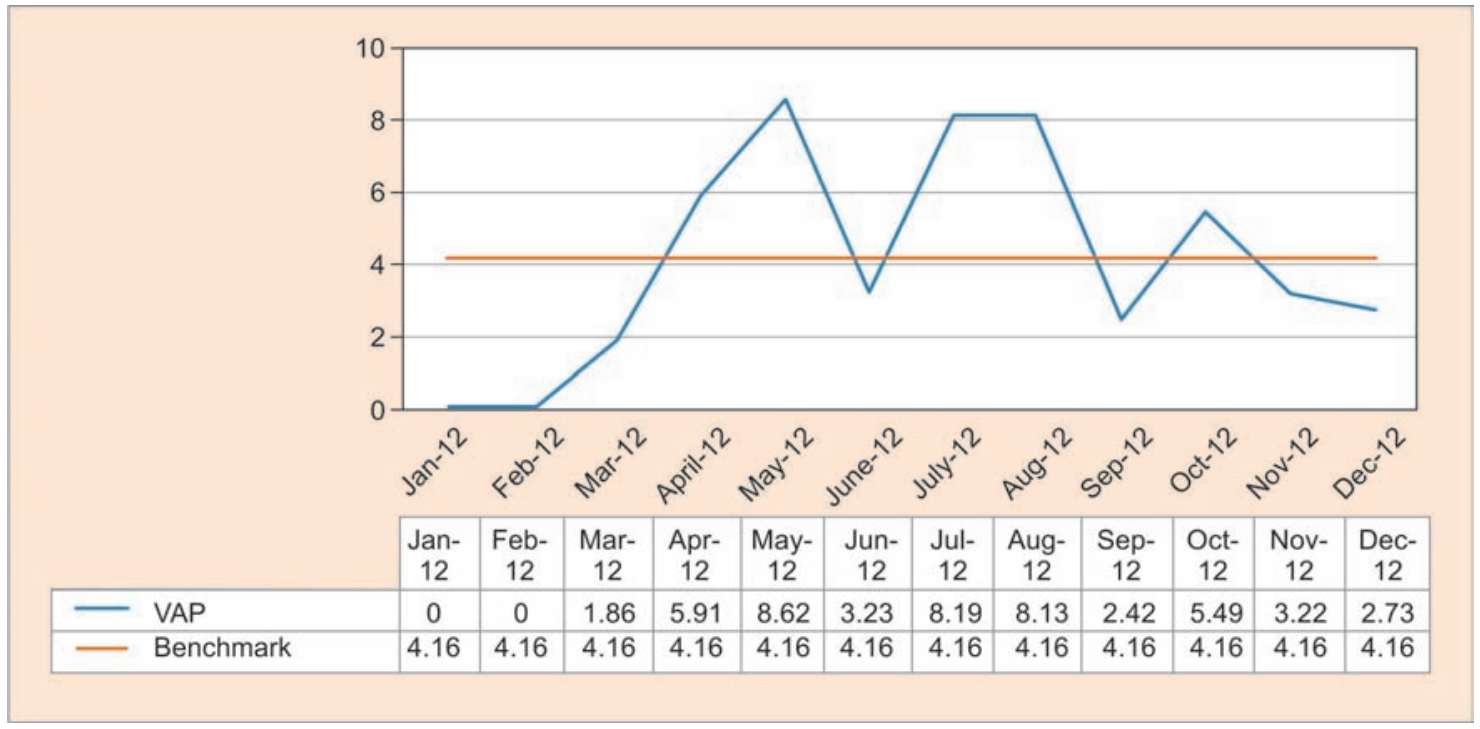

Graph 5: Comparison of annual VAP data with benchmark

\section{Surgical Site Infection (SSI)*}

\section{Incisional}

Superficial Incisional SSI: Infection occurs within 30 days after the operation, and infection involves only skin or subcutaneous tissue of the incision and at least one of the following:

- Purulent drainage from the superficial incision.

- Organisms isolated from an aseptically obtained culture of fluid or tissue from the superficial incision.

- Superficial incision was deliberately opened by surgeon, and is culture positive or not cultured. The patient has at least one of the following signs or symptoms of infection: Pain or tenderness, localized swelling, redness, or heat. A culture-negative finding does not meet these criteria.
- Diagnosis of superficial incisional SSI by the surgeon or attending physician.

Deep Incisional SSI: Infection occurs within 30 to 90 days after the operative procedure and involves deep soft tissues of the incision (e.g., fascial and muscle layers) and patient has at least one of the following:

- Purulent drainage from the deep incision, but not from the organ/space component of the surgical site.

- A deep incision spontaneously dehisces or is deliberately opened by a surgeon and is culture positive or not cultured, and patient has at least one of the following signs or symptoms: Fever $\left(38^{\circ} \mathrm{C}\right)$, localized pain, or tenderness. A culture-negative finding does not meet these criteria.

- An abscess or other evidence of infection involving the deep incision is found on direct examination, 
during invasive procedure, or by histopathological or imaging test.

- Diagnosis of a deep incisional SSI by a surgeon or attending physician.

\section{Organ/Space SSI}

An organ/space SSI involves any part of the body, excluding the skin incision, fascia, or muscle layers, i.e., opened or manipulated during the operative procedure limited to the following infections:

- Osteomyelitis

- Mediastinitis

An organ/space SSI must meet the following criterion: Infection occurs within 30 to 90 days after the operative procedure and patient has at least one of the following:

- Purulent drainage from a drain, i.e., placed through a stab wound into the organ/space

- Organisms isolated from an aseptically obtained culture or fluid or tissue in the organ/space

- An abscess or other evidence of infection involving the organ/space, i.e., found on direct examination, during invasive procedure, or by histopathologic or imaging test 4 diagnosis of an organ/space SSI by a surgeon or attending physician

The SSI rate in hospital is calculated by below given formula:

$$
\frac{\text { Number of SSI cases }}{\text { Total number of surgeries }} \times 100
$$

The mean for SSI was 1.16, which was less than the benchmark set (Graph 6). The deviation was observed only in the month of January. The reason could not be tracked. So, all possible measures were taken and trend was maintained for the rest of the year. The rate was less than the benchmark set.

\section{Fall Rate}

Fall rate was calculated specifically for the ICU by the formula given below:

Number of episodes of fall of patients without injury Total number of patient discharged/death

The mean for fall rate in ICU was 0.05, which was slightly higher than the benchmark set (Graph 7). The minimum fall observed in ICU was due to patient drowsiness. Measures were taken by the organization and trend shows that it was quite effective. The benchmark set by organization was the minimum, and hospital was able to maintain that.

\section{Reintubation Rate}

Reintubation of patients leads to prolonged stay, longer ventilation, and higher nosocomial infection.

Reintubation was calculated by below formula:

$$
\frac{\text { Number of patients reintubated }}{\text { Number of patients extubated }} \times 100
$$

The benchmark set was very high (Graph 8). According to the Indian Society of Critical Care Medicine (ISCCM), the benchmark for reintubation rate is $12 \%$ of total extubated patients, whereas the hospital kept it as 0 , which was good; however, to maintain that requires a lot of effort. Though the rates were little higher than the benchmark, efforts were taken to reduce it further.

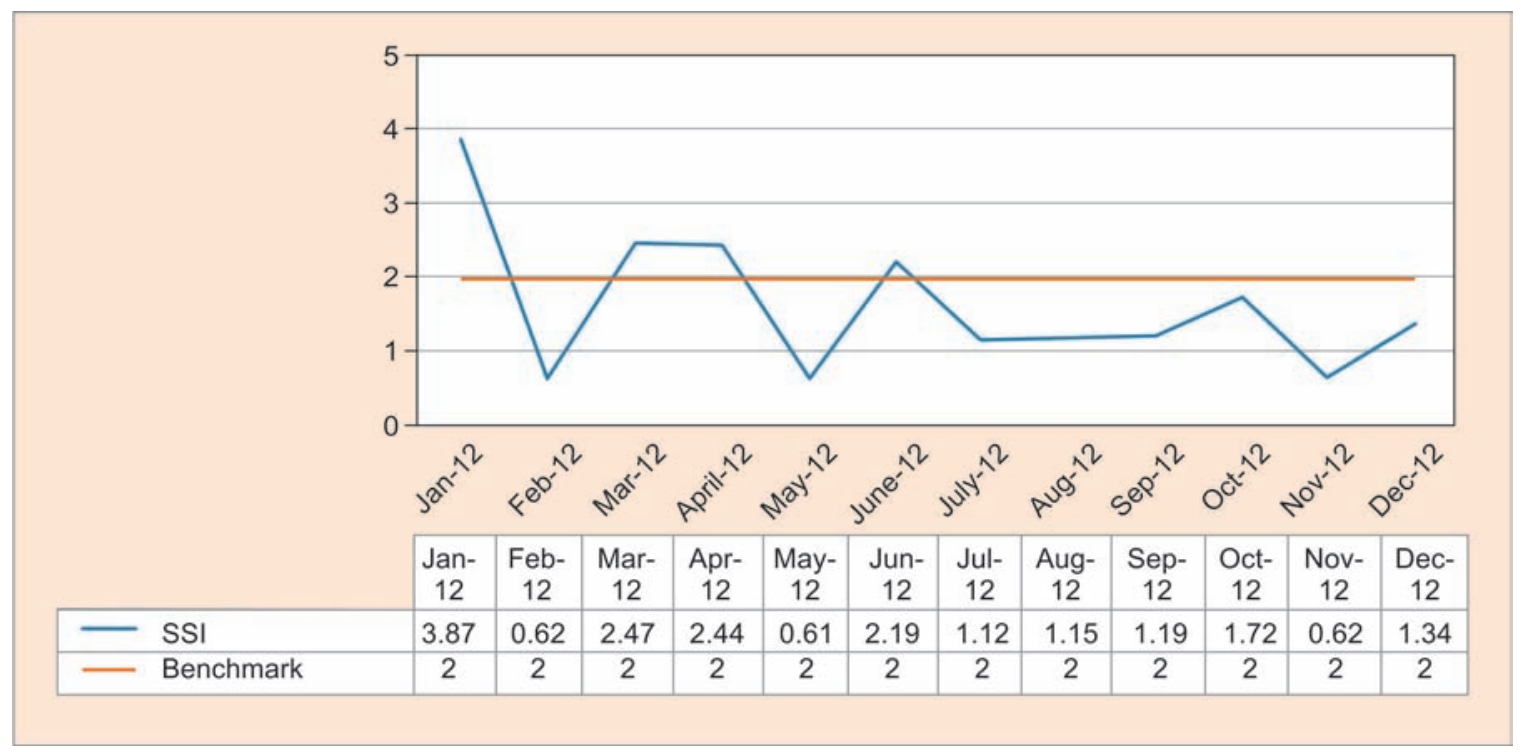

Graph 6: Comparison of annual SSI data with benchmark 


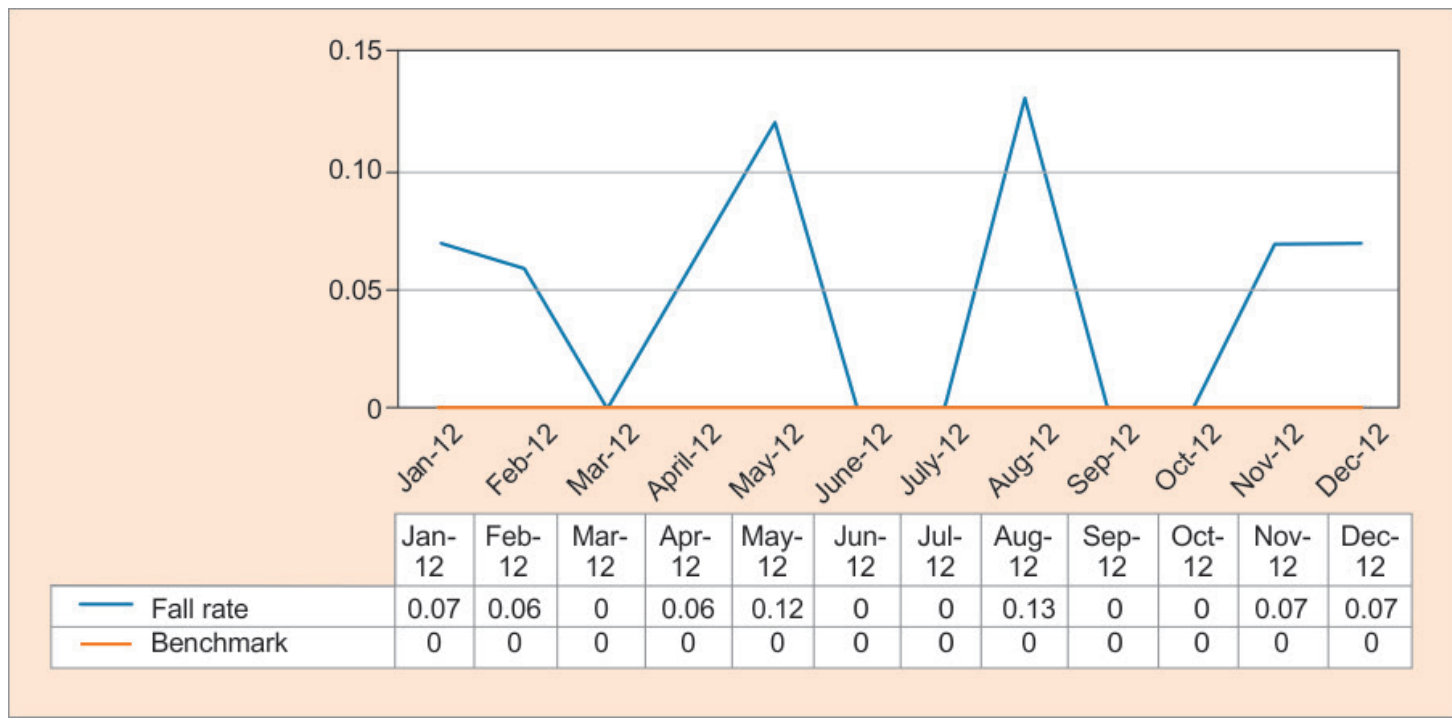

Graph 7: Comparison of annual fall rate data with benchmark

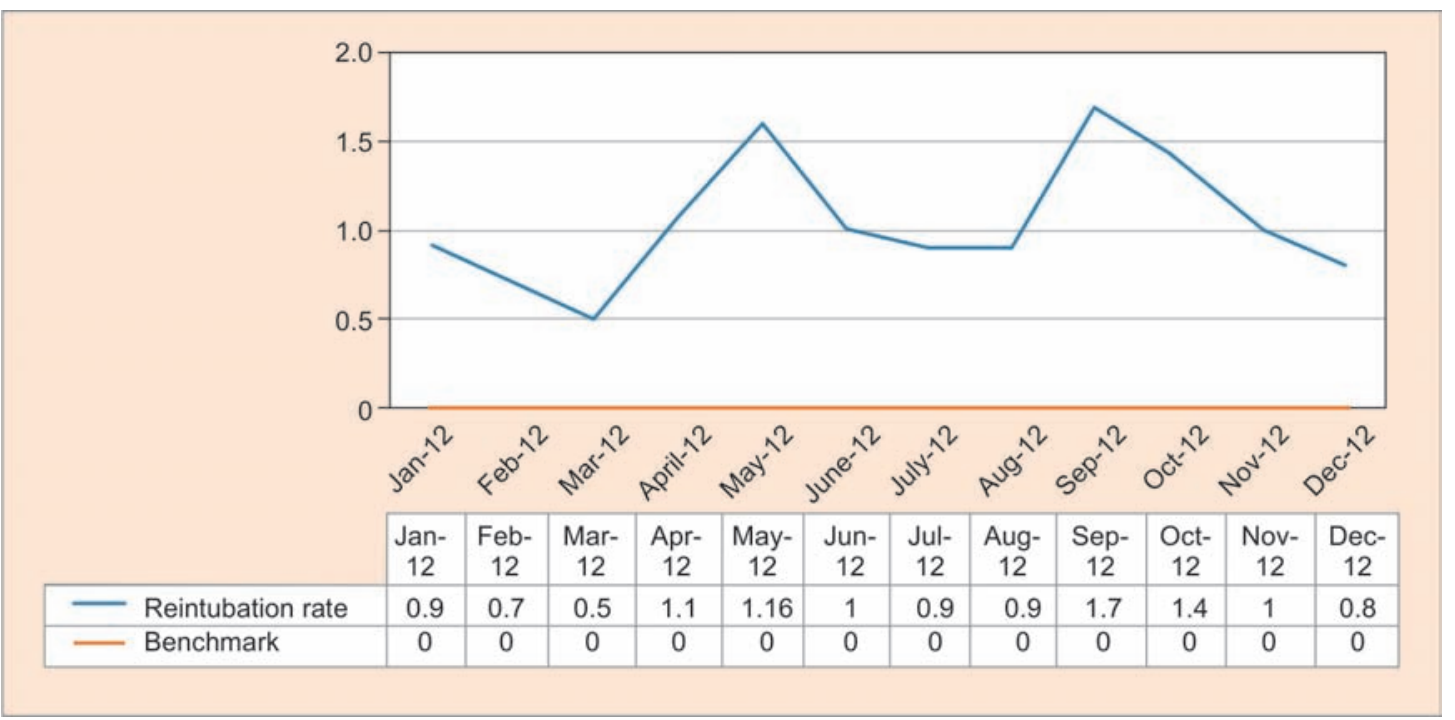

Graph 8: Comparison of annual data of reintubation rate with benchmark

\section{Rate of Return to the ICU within 48 Hours}

The rate of return to ICU was calculated by below formula:

Number of cases return to ICU within 48 hours

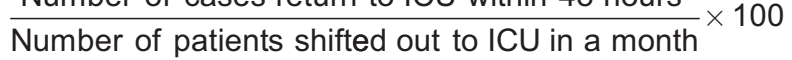

According to the ISCCM, the benchmark for return to ICU is $5 \%$ of the total patients shifted out from the ICU (Graph 9). The organization kept the benchmark as 0 , which, to an extent, the organization was able to follow.

The mean for return to ICU was 0.68 , whereas the benchmark set was 0 . Very less variation from benchmark was observed.

\section{Mean, Median, and Standard Deviation of Indicator}

The statistical analysis showed the variation from benchmark (Table 6). The table clearly showed that CAUTI and
CLABSI had maximum deviations from benchmark. The reason for deviation has been discussed earlier.

Incidence of pressure sores and fall rate has minimal deviation from the benchmark, as the increase in rates was detected in early phase and measures were taken.

\section{Qualitative Methods}

The quality team was interviewed for achieving objectives 2(a) and 2(b). All the members of the quality team were interviewed on quality and accreditation. The interview was semistructured; the summary of each question is written below.

\section{Semi-structured Interview}

\section{For Quality Executives and Doctors}

- What does quality in health care mean to you?

- How does it affect the image of the hospital? 


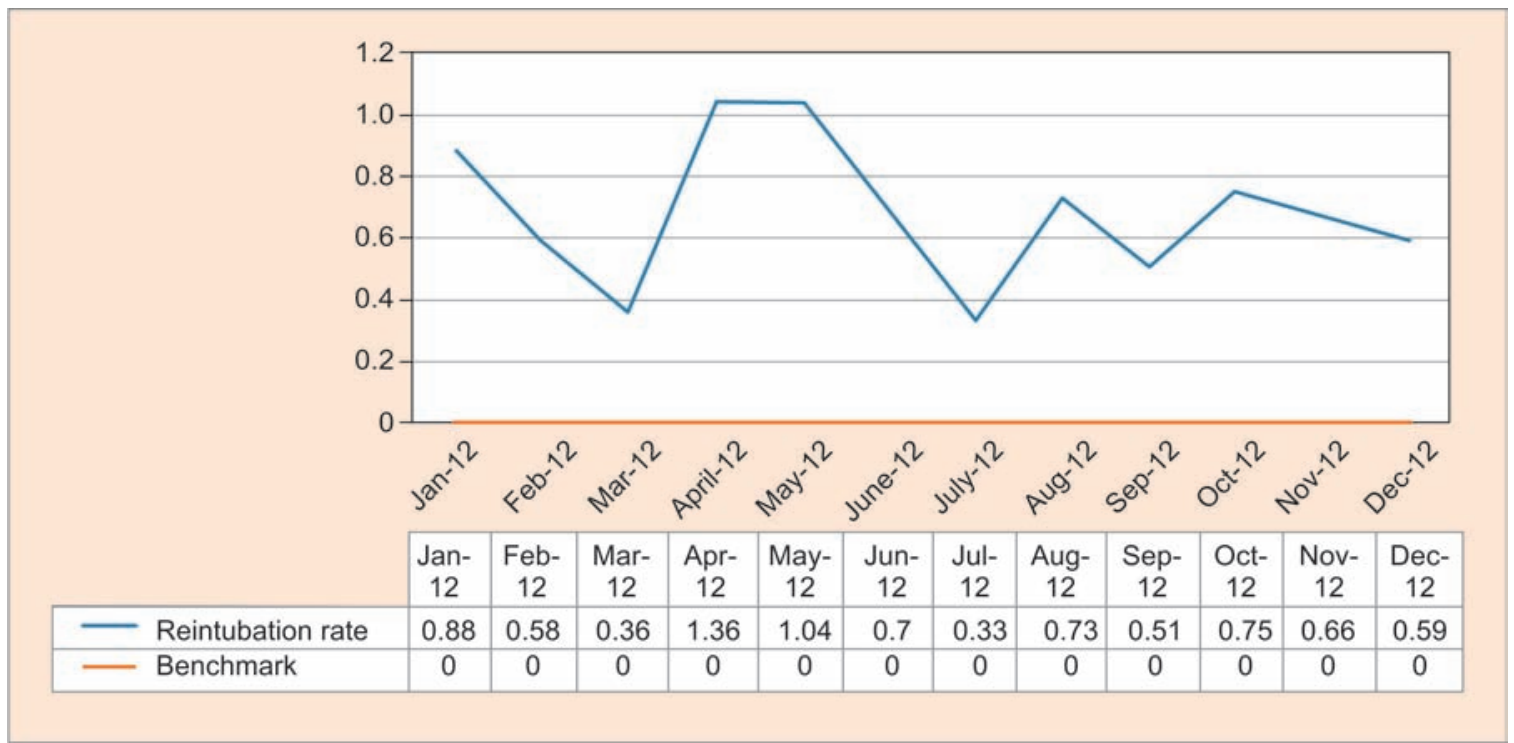

Graph 9: Comparison of annual data of return to ICU with benchmark

Table 6: Statistical analysis of NABH indicators

\begin{tabular}{|c|c|c|c|c|}
\hline Indicator & Mean & Median & $\begin{array}{l}\text { Standard } \\
\text { deviation }\end{array}$ & Benchmark \\
\hline Needle stick injury & 0.04 & 0.04 & 0.000237 & 0.01 \\
\hline CLABSI & 4.62 & 4.93 & 1.2 & 2.79 \\
\hline $\begin{array}{l}\text { Incidence of pressure } \\
\text { sore }\end{array}$ & 0.15 & 0.055 & 0.2205 & 0.5 \\
\hline CAUTI & 0.905 & 0.93 & 0.863 & 4.02 \\
\hline VAP & 4.15 & 3.225 & 3.0662 & 4.16 \\
\hline SSI & 1.16 & 1.27 & 0.0097 & 2 \\
\hline Fall rate & 0.05 & 0.06 & 0.000478 & 0 \\
\hline Reintubation rate & 1.04 & 0.95 & 0.003 & 0 \\
\hline Return to ICU & 0.68 & 0.68 & 0.0022 & 0 \\
\hline
\end{tabular}

- How accreditation helps in maintaining the quality?

- Why do you think-is it necessary to maintain quality standards after accreditation?

- What all measures are taken by organization for continuous quality improvement after accreditation?

- What are your suggestions to improve the quality standards in ICU?

\section{Meaning of Quality in Health Care}

The interview data analysis showed that the answers were very common among the quality team, which can summarized as achieving excellent standard of care and patient satisfaction.

\section{Suggestions to Improve Quality in the ICU}

The answers were very different from different members. For instance, the nursing educator insisted on continuous medical education, whereas the head of the microbiology department insisted to keep an eye on infection rates of the ICU. Continuous medical education, team work, and staff involvement are basic aspects, which were narrated by the quality officers. Other than these, protocols and policies for the ICU are necessary and it must be made mandatory for the staff to read and to follow them.

Patient feedback was one common answer given by all the members. Patient feedback on services will improve the quality of care given. Regular internal audits, surprise checks, maintaining records of all NABH indicators, and documentation will be of great help.

\section{CONCLUSION}

Objective 1: To assess the policies of the hospital with the standards of NABH in the ICU.

\section{Checklist}

The surprise checks in the three ICUs of the hospital showed that standard procedures were not followed in the hospital. The wide variations in standard compliance showed that the staff were not aware of the standard procedures to be followed in the ICU. This clearly depicts that organization was not able to maintain the standards required for accreditation. Lack of awareness of staff regarding SOPs, lack of motivation to follow the standard procedure, excess workload, and shortage of staff in the ICU were few reasons for noncompliance. If a hospital is accredited, it should maintain and follow the standards, and efforts should be made for continuous improvement.

\section{National Accreditation Board for Hospital and Health Care Providers Indicators}

Analysis of indicators showed that only four of nine indicators were having a mean of less than benchmark; other five indicators showed huge variations from benchmark 
decided by hospital. The SSI, pressure sores, and CAUTI were lower than the benchmark set. It showed that organization was making continuous efforts to improve the standards.

In a few cases, the hospital was not able to maintain the predefined values. The reason was different in all cases, but few were common for all, which include:

- Standard operating procedures were not available in every department.

- Staff was not aware about policy and procedures.

- Lack of motivation for following standard policies and procedures.

- Lack of continuous education for staff regarding continuous quality education.

- Staff shortage in the ICU.

- High attrition rate in the ICUs.

- Absence of clear communication between departments.

- Increased patient stay.

Objective 2(a): To assess management perception toward quality management in post-NABH accreditation period.

Objective 2(b): To assess the measures taken by the hospital to maintain the quality.

The interview was conducted to know the management's perception toward accreditation, quality, and patient satisfaction. Management showed a positive attitude toward quality and accreditation. According to them, accreditation plays a vital role in maintaining quality in an organization, but organization was not able to maintain the standard as expected. According to management, various measures were taken to maintain and continuously improve the standards.

The measures taken by organization were continuous medical education, employee engagement, ICU incentives for staff, making SOPs for departments, internal audits, etc.

By looking at the data analysis, it is very clear that the organization knows the need of maintaining the standards but was not able to maintain for various reasons.

Objective 3: To assess patient/relative satisfaction in the ICU of an NABH-accredited hospital toward quality of care given.
The analysis of patient satisfaction questionnaire showed that patients were highly satisfied with cleanliness and hygiene services of the hospital. All the patients' responses were positive regarding the entire gamut of questions related to hygiene and sanitation. The questionnaire analysis showed that patient satisfaction level was 60 to $65 \%$ in case of services, $100 \%$ for hygiene, and $53.80 \%$ for information given regarding treatment choice.

When a hospital goes for accreditation, the quality of care given and patient satisfaction level increase, whereas the analysis shows that patients were not satisfied with services provided and information shared, but highly satisfied with hygiene and cleanliness. Accreditation increases satisfaction level in patients, but, in this case, the patients were not satisfied with the services and information given to them.

\section{REFERENCES}

1. Joint Commission. Oakbrook Terrace (IL): Joint Commission; 2013. [cited 2013 Nov 8]. Available from: http://en.wikipedia. org/wiki/Joint_Commission.

2. NABH. New Delhi: National Accreditation Board for Hospital \& Health Care Organization. 2013. [cited 2013 Sep 25]. Available from: http://www.nabh.co/main/hospitals/ accredited.asp.

3. Shaw, C. Quality and accreditation in health care services. Geneva: World Health Organization; 2003.

4. Tabrizi JS, Gharibi F, Wilson AJ. Advantage and disadvantage of health care accreditation models. Health Promot Perspect 2011 Jul;1(1):1-31.

5. Gopinathan S. Compare the current practice of SreeRenga Hospitals in Access, Assessment and Continuity of care and care of patient against $\mathrm{NABH}$ standards in the process of NABH accreditation. 2010.

6. Salmon, JW.; Heavens, J.; Lombard, C.; Tavrow, P. The impact of accreditation on quality of hospital care: KwaZulu-Natal Province,. Republic of South Africa.. Quality Assurance Project. Bethesda (MD): University Research Co., LLC; 2003.

7. El-Jardali F,Jamal D, Dimassi H, Ammar W, Tchaghchaghian V. The impact of hospital accreditation on quality of care: perception of Lebanese nurses. Int J Qual Health Care 2008 Oct;20(5):363-371. 